\title{
Possibility of determining soil pH using visible and near-infrared (Vis-NIR) spectrophotometry
}

\section{Authors Info}

\section{Z. Tümsavaş}

Department of Soil Science and Plant Nutrition, Faculty of Agriculture, Uludag University, Bursa, 16059, Turkey

*Corresponding Author Email : zeynal@uludag.edu.tr

\section{Key words}

PLS regression analysis,

Reflectance,

Soil pH,

Vis-NIR spectrophotometry

Publication Info

Paper received : 12.09 .2016

Revised received : 25.06.2017

Accepted : 27.06.2017

\section{Abstract}

Aim : The present study was conducted to investigate possibility of using fiber-optic visible and nearinfrared (Vis-NIR) spectrophotometry for determining soil pH.

Methodology : Diffuse reflectance spectra of 272 soil samples taken at a depth of $0-20 \mathrm{~cm}$ from cultivation soil in Bursa Province, Turkey, were measured in the laboratory to determine soil pH. Before apartial least square (PLS) analysis of the reflectance spectra values was conducted, all of them were randomly split into calibration (70\%) and validation (30\%) sets. A model for the prediction of soil $\mathrm{pH}$ from reflectance spectra values obtained from spectrophotometry was established using PLS regression analyses with full crossvalidation.

Results : The regression value $\left(R^{2}\right)$, root mean square error of prediction (RMSEP) and residual prediction deviation (RPD) of established model were found to be $0.69,0.70 \%$, and 1.413 , respectively.

Interpretation : The results demonstrated a moderate level of success for the model in predicting soil pH.

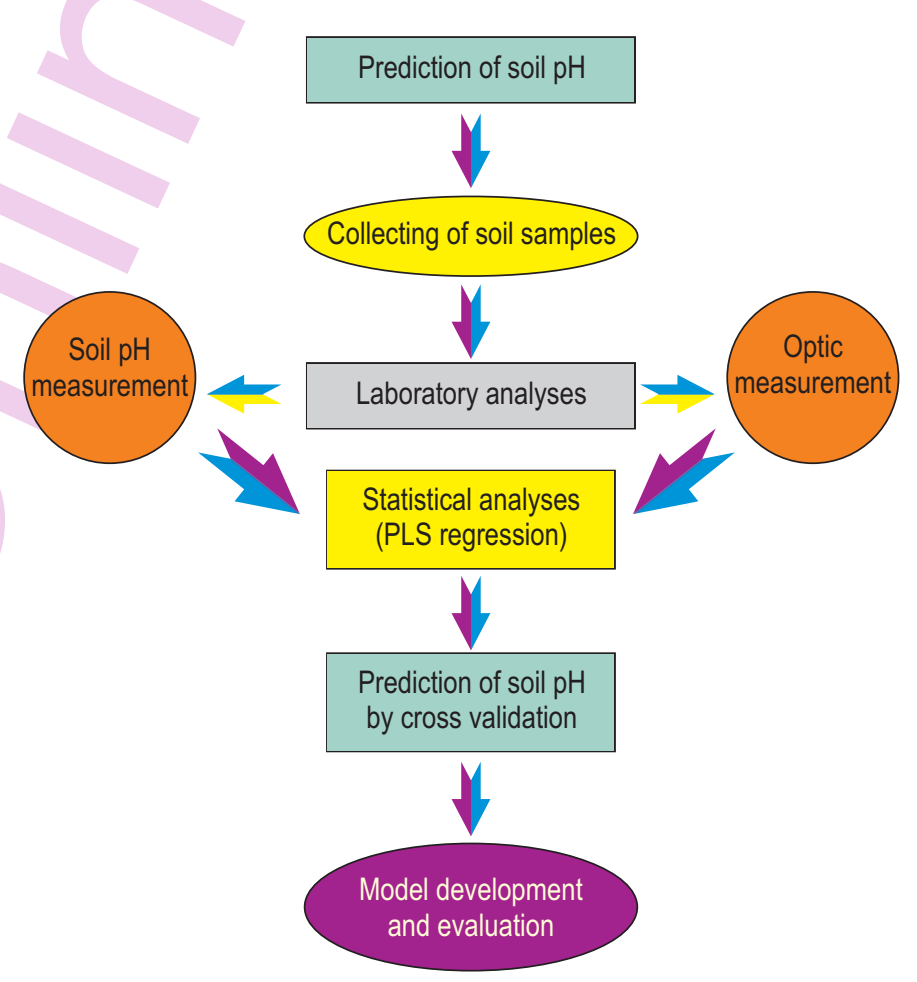




\section{Introduction}

The main objective in agricultural production is to increase economic efficiency. In order to attain economic efficiency, accurate and balanced use and management of main elements of the agricultural environment, the soil and its agricultural inputs is required. The world population continues to grow and the areas where agriculture can be carried out are decreasing day by day. This situation compulsorily demands more careful use of resources. In traditional soil management, the production environment is handled uniformly and manipulated using a single approach. However, the physical nature of agriculture land and geographical changes limit the effects of land management. Even soils in the same field are highly variable in terms of properties, especially in their spatial location. By carrying out judicious soil management practices, potential productivity of the soil and the main goal of agricultural production can be achieved. Although producers obtain varying yields from different parts of a field, or from fields having different soil composition, they are not evaluating this information in terms of production (Vatandaş et al., 2005).

It is difficult and complicated to fully understand the processes that take place in the soil, and their mechanisms. Many traditional soil analysis methods are used to establish relationships between the physical and chemical properties of the soil and individual soil components. However, the mutual interactions of the complicated structures of the land and its many constituent parts are often ignored. In order to use the soil more efficiently, and at the same time for protecting it for future generations, there is a need to investigate the possibilities of using modern technologies to improve analysis methods. We need to better understand the whole system and natural resources and to be able to evaluate and monitor the soil (Viscarra Rossel et al., 2006; Feyziyev et al., 2016).

Many soil properties affect soil productivity. One of these is soil pH. The soil pH affects the availability of nutrients in soil, anion and cation balance, soil structure, variety of microbial organisms and their activities and plant growth. Usually, for determination of soil $\mathrm{pH}$ traditional methods, using varying suspensions of soilwater or soil-salt solutions, saturation extract and saturation mud, are employed. In general, these methods are time consuming and expensive and require excessive labor and the use of chemicals. This means that effective and extensive use of analysis is reduced, while the cost is increases. Therefore, new approaches which are fast and inexpensive are needed as convenient alternatives for determination of soil pH.Janik et al. (1998) reported that visible (Vis), near infrared (NIR) and mid infrared (MIR) spectrophotometry, nuclear magnetic resonance (NMR) and mass spectrophotometry (MS) could replace traditional laboratory soil analysis methods as alternative techniques. These methods are based on investigated material and do not cause any destruction or harmful effect, make it possible to maintain the basic integrity of the soil system. As spectroscopic methods analyze samples quickly, yield results in a short time, and do not require preprocessing and chemical extraction, they offer significant advantages over conventional soil analysis methods. The vis-NIR spectrophotometric method is easier than conventional soil analysis and in addition can give more accurate results (Viscarra Rossel et al., 2006). McCauley et al. (1993) reported that in the analysis of soil organic carbon, the visible spectroscopic method gave more accurate results as compared to the conventional dichromate method. The sensitivity of the mid infrared-partial least squares (MIR-PLS) method used for prediction of soil $\mathrm{pH}$ and lime requirement was found to be higher than the that of the conventional method of analysis (Viscarra Rossel et al., 2001).Another advantage of the spectroscopic method is that it has adaptable potential and can be mounted on agriculture vehicles for use in the field. This situation provides with it significant advantages. With the proliferation of precision agriculture in many countries of the world, environmental monitoring and spatial data used in modeling studies can enable the effective use of spectroscopic methods for quality and costeffective data acquisition in large number of areas.

The aim of this study was to investigate the use of fiber optic Vis-NIR spectrophotometry for estimating soil pH.

\section{Materials and Methods}

Soil sample collection and chemical analysis : Soil samples were taken from 272 different points at a depth of $0-20 \mathrm{~cm}$ with different land use types in the Bursa region. Each soil samples was placed in a nylon plastic bag, labeled and transported to laboratory. The samples were spread out in shade and all owed to dry or to air-dry under atmospheric conditions in laboratory. They were then prepared for analysis by crushing with a mallet, and then passing through a 2-mm sieve. A part of each soil sample prepared for analysis was read spectrophotometrically, while another part was used for $\mathrm{pH}$ measurement (McLean, 1982). The $\mathrm{pH}$ of soil samples was determined in suspension in 1:2 ratio of soil:water.

Some descriptive statistical data such as the minimum, maximum, mean and standard deviation values of $\mathrm{pH}$ of soil samples are given in Table 1

Optical measurement : A vis-NIR fiber-optic spectrophotometer (350-2500 nm) (LabSpec 2500 Near Infrared Analyzer, Analytical Spectral Devices, Inc. USA) was used for measuring light reflectance values of soil samples. The spectrophotometer utilized a Si array detector at a wavelenght of 350-1000 nm and two Peltier-cooled InGaAs (Indium gallium arsenide) sensors for wavelengths of $1000-1800 \mathrm{~nm}$ and $1800-2500 \mathrm{~nm}$. The device had a sampling range of $1 \mathrm{~nm}$ and a spectral resolution of $3 \mathrm{~nm}$ for a wavelength of up to $700 \mathrm{~nm}$ and $10 \mathrm{~nm}$ for a wavelength range of $1400-2100 \mathrm{~nm}$. 
Table 1 : Some descriptive statistics for $\mathrm{pH}$ of soil samples

\begin{tabular}{ll}
\hline Statistics & $\mathrm{pH}$ \\
\hline Minimum & 3.60 \\
Maximum & 8.10 \\
Mean & 5.90 \\
Standard deviation & 1.22 \\
\hline
\end{tabular}

Table 2 : Evaluation table for model setting over residual prediction deviation (RPD)*

\begin{tabular}{|c|c|c|}
\hline RPD & Model/Prediction & Application \\
\hline$<1$ & Very poor & Not applicable \\
\hline $1.0-1.4$ & Poor & $\begin{array}{l}\text { Can only be considered for high } \\
\text { or low values }\end{array}$ \\
\hline $1.4-1.8$ & Medium & Evaluation and correlation \\
\hline $1.8-2.0$ & Good & Quantitative evaluation possible \\
\hline $2.0-2.5$ & Very Good & Quantitative model /prediction \\
\hline$>2.5$ & Excellent & Excellent model/prediction \\
\hline
\end{tabular}

* as compiled by Viscarra Rossel et al. (2006)

Table 3 : Statistics for soil pH prediction

\begin{tabular}{ll}
\hline Statistics & Result \\
\hline $\mathrm{R}^{2}$ & 0.687 \\
Standard Error & 0.496 \\
Standard deviation & 0.989 \\
Root mean square error & 0.700 \\
of prediction (RMSEP) & \\
Residual prediction & 1.413 \\
deviation (RPD) & \\
Slope & 0.54 \\
\hline
\end{tabular}

The most important step in obtaining accurate results with vis-NIR absorption spectrometer reflectance is the pre-treatment of soil samples before the reflectance values are obtained.The pre-treatment applied here included drying, pulverizing-crushing and sieving operations. Two of the advantageous aspects of this method are that no chemicals were used in the pretreatment and that the measurements took as little as a few seconds (Stenberg et al., 2010). Before spectral measurements were taken, after drying and crushing, each soil sample was passed through a 2$\mathrm{mm}$ sieve, placed in a plastic container and the surface was then leveled with a spatula. The soil samples in the plastic containers were placed in direct contact with high-intensity beam source of spectrophotometer and three separate spectrometer measurements were taken for each sample. After taking the average of these three spectrophotometric measurement values, these mean values were used for statistical analysis to establish a model for soil $\mathrm{pH}$.

Statistical analysis of reflectance values : For comparison of soil $\mathrm{pH}$ reference values obtained from pretreatment with spectral reflectance values, it was necessary to conduct their statistical analyses and create a model, and for this, the Unscrambler® (Version 9.8, Camo A/S, Oslo, Norway) was used. With the aim to be able to create a better model from the reflectance values, the reflectances were subjected to statistical preprocessing. By applying different preprocesses to the reflectance data, an attempt was made to obtain the best regression result. The spectrophotometer used had a wavelength of $350-2500 \mathrm{~nm}$, and the preprocessing began with reducing the number of wave lengths. In order to do this, the values starting at $350-400 \mathrm{~nm}$ were removed with the aim of reducing noise. Every eight columns of data in the visible (Vis) spectra between $400-700 \mathrm{~nm}$ wave lengths and in the near-infrared (NIR) spectra between 700 $2500 \mathrm{~nm}$ wavelengths were grouped by taking the average of 17 data columns, so the data column to be analyzed was limited to column 147. After the number of wavelengths was determined, the Savitzky-Golay 1st derivative (Savitzky and Golay, 1964) and smoothing procedures were applied. Distribution of data obtained by applying normalization preliminary process to the original reflection values are given in Fig. 1.

The Savitzky-Golay $1^{\text {st }}$ derivative was the method used for the correction of the irregularities of the reflectance data and smoothing was applied in order to even out the positive and negative peaks. Distribution of the data obtained as a result of smoothing and Savitzky-Golay $1^{\text {st }}$ derivative applied following normalization is shown in Fig. 2.

Model establishment: Of the different multivariate methods that can be used in statistical analyses, the partial least square (PLS) method has been reported to give more highly correlated results (Chang et al., 2001; Boğrekci and Lee, 2004; Mouazen et al., 2006). Among the PLS methods, explanatory variables with multiple linear connections, with the help of algorithms, are able to explain both the dependent variable change as well as the change in explanatory variables (Bulut and Alın, 2009). In the initial stage of model building, the sample spectra were divided into calibration (70-80\%) and verification (20-30\%) groups. After this process, the calibration group was subjected to different statistical methods and the $R^{2}$ value was calculated. By applying independent validation (cross-validation) between the verification group and the calibration group, the calibration model was expected to emerge. To determine soil pH in this research, $70 \%$ of the spectra related to soil samples were collected in the calibration group (190 samples), while $30 \%$ (82 samples) were used in the verification group. The groups were randomly selected from a total of 272 soil samples.

Statistical evaluation of the model : The $R^{2}$ value alone is not sufficient to specify the accuracy of calibration model. For this purpose, the root mean square error of prediction (RMSEP) (Eq. 1) and the residual prediction deviation (RPD) (Eq. 2) were evaluated together with $R^{2}$ in order to indicate the validity of model (Viscarra Rossell et al., 2006). 


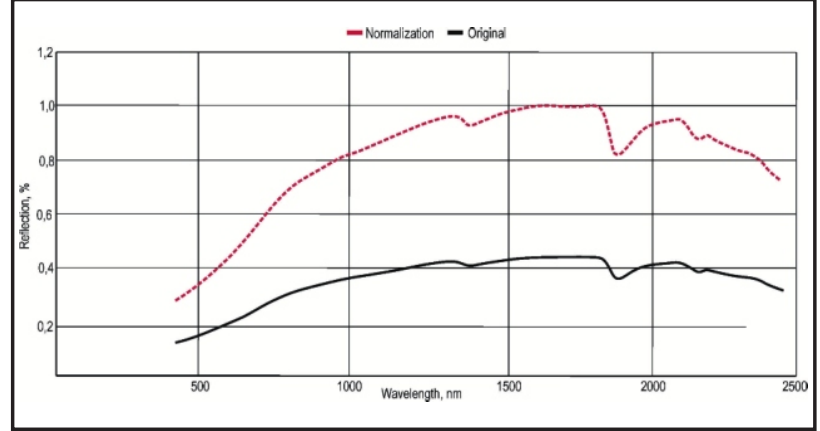

Fig. 1 : Distribution of the original data and the data obtained as a result of normalization process

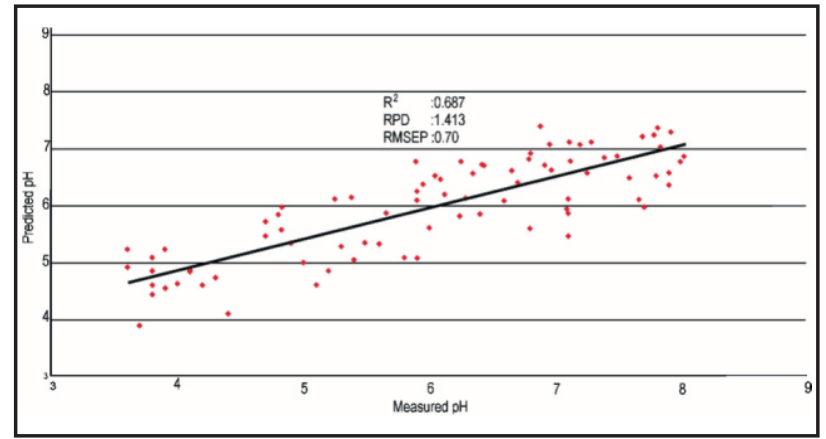

Fig. 3 : Distribution of measured and predicted soil pH

$$
\text { RMSEP }=\sqrt{\left[\frac{\left\{\sum_{i=1}^{n} d_{i}^{2}\right\}}{n}\right]}
$$

where, $\mathrm{n}$ is the number of data, and $\mathrm{d}$ is the difference between the reference measurement and the predicted value.

$$
\mathrm{RPD}=\frac{\text { Standard deviation }}{\text { RMSEP }}
$$

For a successful correlation in agricultural analyses, the union of $R^{2}$ value $\left(R^{2}>0.95\right)$ and $R P D$ value $(R P D>5)$ should occur. However, in case of soil where too many factors are effective, it is difficult to obtain this result. The evaluation of model was made according to the classification system dependent on the RPD values as shown in Table 2 (Viscarra Rossel et al., 2006).

\section{Results and Discussion}

Efforts to take advantage of vis-NIR spectrometer reflectance results to predict the physical and chemical properties of the soil continue to expand. In this study, spectral reflectance values for predicting the $\mathrm{pH}$ value of soil were examined. The results of the statistical analysis evaluation are presented in Table 3. The predictability was assessed by comparing the results of the

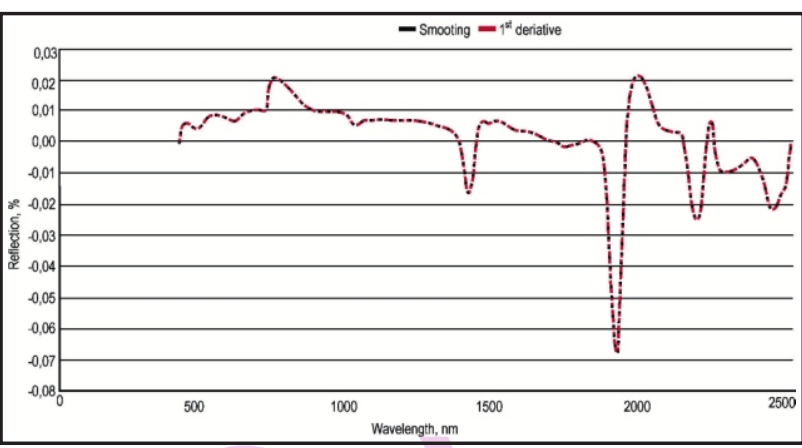

Fig. 2 : Distribution of the data obtained via 1 st derivative and smoothing process

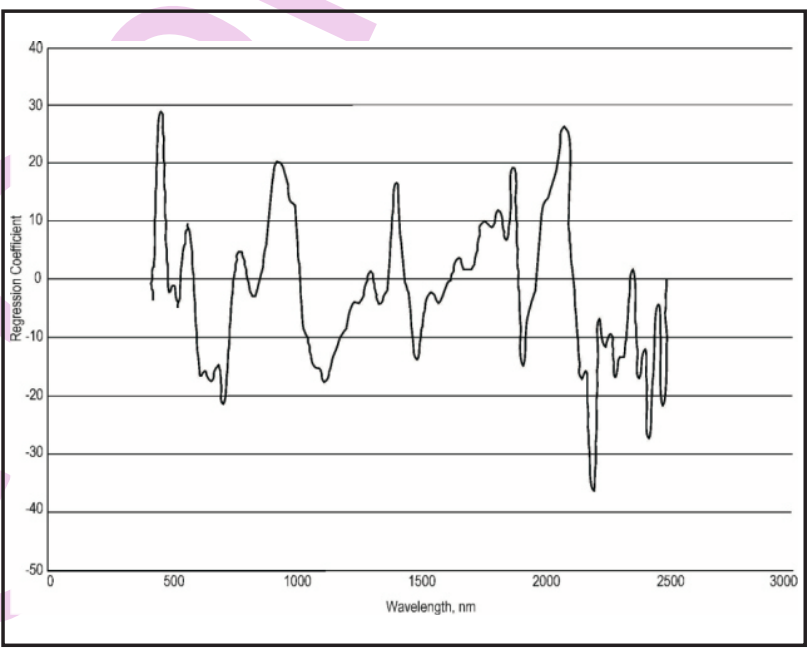

Fig. 4 : Scatter plot of regression coefficient values according to wavelength for predicting the soil pH

$\mathrm{pH}$ analysis of soil samples collected from 272 points with the spectrometer reflectance results.

According to the statistical results obtained in soil $\mathrm{pH}$ evaluation, the $R^{2}$ value was 0.69 and the RPD value 1.413 (Table 3).The RPD evaluation classification for estimating the soil $\mathrm{pH}$ performance given in Table 2 suggests that the values of the model succeeded with a moderate level of correlation. According to the reports of Wenjun et al. (2014), Williams (2003) and Saeys et al. (2005), when the $R^{2}$ value was between 0.66 and 0.81 with the RPD value between 2 and 2.5, a 'good' estimation of the examined variable was possible.In a study using visible and nearinfrared spectrophotometry for the purpose of estimating the soil properties of Azerbaijan Mugan soil, the soil pH was found to have a low predictive value according to the obtained $R^{2}$ value (Feyziye et al., 2016). Tekin et al. (2013) sought to determine the potential of soil $\mathrm{pH}$ measurement for deriving the variable rate lime recommendations in the laboratory and on the ground using visible and near infrared spectrophotometry. In their study, they 
found soil $\mathrm{pH}$ measurements taken in the laboratory to be at 'Excellent' level of prediction $\left(\mathrm{R}^{2}=0.85, \mathrm{RMSEP}=0.18\right.$ and $\mathrm{RPD}=2.52$ ), while measurements made in the field were found to be 'very good' $\left(R^{2}=0.81\right.$, RMSEP $=0.20$ and $\left.R P D=2.14\right)$. As a result, it was concluded that visible and infrared spectrophotometry could be used successfully for the estimation of soil $\mathrm{pH}$.

Wenjun et al. (2014) used vis-NIR spectrophotometry in field and laboratory in order to determine certain soil properties in plowed land. The $\mathrm{R}^{2}$ value for soil $\mathrm{pH}$ was found as 0.82 , while the RPD value was 2.42 , and thus by looking at these values, they were able to predict the soil $\mathrm{pH}$ with approximate quantitative accuracy. Although soil pH is without direct spectral response in the vis-NIR beam range, soil $\mathrm{pH}$ measurements are always more successful as compared to those of soil phosphorus and potassium (Shepherd and Walsh, 2002: Cohen et al., 2005). For this reason, it has been stated that the wavelengths of soil minerals can be a source of relationship with soil pH (Viscarra Rossel and Behrens, 2010).

In several studies, accurate measurements have been obtained with vis-NIR spectrophotometric detection technology for important soil properties such as organic carbon, soil moisture content, total nitrogen and clay content due to the fact that they exhibit direct spectral response to NIR radiation range (Mouazen et al., 2007; Stenberg et al., 2010; Kuang and Mouazen, 2013).However, soil characteristics with response to indirect spectral radiation in the NIR range provide less successful measurement (González et al., 2013: Kodaira and Shibusawa, 2013). The $\mathrm{pH}$ has an indirect spectral radiation in the NIR beam range (Stenberg et al., 2010).

The cross-validation applied between the validation group and the calibration group as an independent validation was revealed as the calibration model. The regression analysis graph in Fig. 3 shows the relationship between the 82 soil samples used in the validation group whose soil $\mathrm{pH}$ was measured in the laboratory and the predicted soil $\mathrm{pH}$ values.

The regression coefficients were obtained between the soil $\mathrm{pH}$ measured in laboratory and the predicted soil $\mathrm{pH}$ according to the variation of different wavelengths measured by vis-NIR spectrophotometry (Fig. 4).

$\mathrm{R}^{2}$ graphics is useful in observing the wavelengths, which is important for predicting the soil pH (Fig.4). Important peak points can be seen in the figure especially in the wavelengths of $459 \mathrm{~nm}, 709 \mathrm{~nm}, 930 \mathrm{~nm}, 2086 \mathrm{~nm}$ and $2205 \mathrm{~nm}$. The most prominent wavelengths from these peak values were those of 460 $\mathrm{nm}, 2086 \mathrm{~nm}$ and $2205 \mathrm{~nm}$.

In conclusion, this study investigated the possibility of using vis-NIR spectrometric reflectance values in determining soil $\mathrm{pH}$. By applying full cross-validation PLS regression analysis to the reflectance values obtained from spectrophotometry, a model was established for soil $\mathrm{pH}$. In the results obtained from statistical analysis, the $R^{2}$ value of established model was 0.69 , the RMSEP value was $0.70 \%$ and the RPD value was 1.413 , respectively. According to the findings, the evaluation capability result was achieved with a moderate correlation of performance success of the model for estimating soil $\mathrm{pH}$. However, if the color, texture, moisture content, etc, that affect the reflectance values are to be considered, there is a need to establish models in which their impact ratings can be evaluated.

Increasingly, spectrophotometric methods with applications in a number of areas also provide significant advantages in determining different soil properties in the field of agriculture. Although there has been much research on the determination of soil properties with vis-NIR spectrophotometry, additional research is needed covering different climate, plant, soil type and geomorphological conditions in order to develop and demonstrate the validity and effectiveness of these methods. Moreover, in addition to the data on soil properties examined using this method and with reference to prepared soil maps, further research that considers agricultural inputs applied to the soil (e.g.,fertilizer treatment, pesticide, irrigation) is needed in order to reveal their effects on the quality and quantity of agricultural yield.

\section{References}

Bogrekci, I. and W.S. Lee: Spectral signatures of common phosphate in soils and their effect on absorbance spectra of soil samples with different phosphorus concentration. Annual International Meeting, Ottawa, Ontario, Canada, pp. 1-11, (2004).

Bulut, E. and A. Alın: Comparison of partial least squares regression method algorithms: Nipals and PLS-Kernel and an application. Dokuz Eylül Üniversity, Faculty of Economics and Administrative Sciences Journal, 24, 127-138 (2009) (in Turkish).

Chang, C.W., D.A. Laird, M.J. Mausbach and C.R. Hurburgh: Nearinfrared reflectance spectroscopy-principal components regression analyses of soil properties. Soil Sci. Soc. Am. J.,65, 480-490 (2001).

Cohen, M.J., J.P. Prenger and W.F. DeBusk: Visible-near infrared reflectance spectroscopy for rapid, nondestructive assessment of wetland soil quality. J. Environ Qual. 34, 1422-1434 (2005).

Feyziyev, F., M. Babayev, S. Priori and G. L'abate: Using visible-near infrared spectroscopy to predict soil properties of mugan plain, Azerbaijan. Open J. Soil Sci., 6, 52-58 (2016).

González, O.M., B. Kuang, M.Z. Quraishi, M.Á.M. Garcaí and A.M. Mouazen: On-line measurement of soil properties without direct spectral responses in near infrared spectral range. Soil Till. Res., 132, 21-29 (2013).

Janik, L.J., R.H. Merry and J.O. Skjemstad: Can mid İnfrared diffuse reflectance analysis replace soil extractions? Aust. J. Exp. Agric., 38, 681-696 (1998).

Kodaira, M. and S. Shibusawa: Using a mobile real-time soil visible-near Infrared sensor for high resolution soil property mapping. Geoderma, 199, 64-79(2013).

Kuang, B. and A.M. Mouazen: Effect of spiking strategy and ratio on 
calibration of on-line visible and near infrared soil sensor for measurement in european farms. Soil Till. Res., 128, 125-136 (2013).

McCauley, J.D., B.A. Engel, C.E. Scudder, M.T. Morganand and P.W. Elliot: Assessing the spatial variability of organic matter. American Society of Agricultural Engineers, St. Joseph, MI, USA. pp. 931555 (1993).

McLean, E.O.:Soil pH and lime requirement. In: Methods of Soil Analysis. (Ed.: A.L. Page et al.). $2^{\text {nd }}$ Edn., Part 2. Agron. Monogr. 9. ASA and SSSA, Madison, WI, pp. 199-224 (1982).

Mouazen, A.M., R. Karoui, J. De Baerdemaeker and H. Ramon: Characterization of soil water content using measured visible and near infrared spectra. Soil Sci. Soc. Am. J., 70, 1295-1302 (2006).

Mouazen, A.M., M.R. Maleki, J. De Baerdemaeker and H. Ramon: Online measurement of some selected soil properties using a VISNIR sensor. Soil Till. Res., 93, 13-27 (2007).

Saeys, W., A.M. Mouazen and H. Ramon: Potential for onsite and online analysis of pig manure using visible and near infrared reflectance spectroscopy. Biosyst. Eng., 91, 393-402 (2005).

Savitzky, A. and M.J.E. Golay: Smoothing and differentiation of data by simplified least squares procedures. Anal. Chem., 36, 1627-1639 (1964).

Shepherd, K.D. and M.G. Walsh: Development of reflectance spectral libraries for characterization of soil properties. Soil Sci. Soc. Am. J. 66, 988-998 (2002).

Stenberg, B., R.A. Viscarra Rossel, A.M. Mouazen and J. Wetterlind: Visible and near infrared spectroscopy in soil science. Adv. Agron.,
$107,163-215(2010)$

Tekin, Y., B. Kuang and A.M. Mouazen: Potential of on-line visible and near infrared spectroscopy for measurement of $\mathrm{pH}$ for deriving variable rate lime recommendations. Sensors, 13, 10177-10190 (2013).

Vatandaş, M., M. Güner and U. Türker: Precision farming tecniques. Union of Chambers of Turkish Engineers and Architects, The Chamber of Agricultural Engineers, 6th Technical Congress, Ankara, pp. 347-365 (2005) (in Turkish).

Viscarra Rossel, R.A. and T. Behrens: Using data mining to model and interpret soil diffuse reflectance spectra. Geoderma, 158, 46-54 (2010).

Viscarra Rossel, R.A., D.J.J. Walvoort, A.B. McBratney, L.J. Janik and J.O. Skjemstad: Proximal sensing of soil $\mathrm{pH}$ and lime requirement by mid infrared diffuse reflectance spectroscopy. In: Third european conference on precision agriculture (3 ecpa) :Proceedings, (Eds.: G. Grenier and S. Blackmore), vol. 1, Agro Montpellier, pp.497-502. (2001).

Viscarra Rossel, R.A., D.J.J. Walvoort, A.B. McBratney, L.J. Janik and J.O. Skjemstad: Visible, near Infrared, mid infrared or combined diffuse reflectance spectroscopy for simultaneous assessment of various soil properties. Geoderma, 131, 59-75 (2006).

Wenjun, J., S. Zhou, H. Jingyi and L. Shuo: In situ measurement of some soil properties in paddy soil using visible and near-infrared spectroscopy. Plos one, 9, 1-11 (2014).

Williams, P.:Near-infrared Technology-getting the best out of light. PDK Grain, Nanaimo, Canada (2003). 